\title{
Performance Evaluation and Sensitivity Analysis of Rural Land Circulation Mode
}

\author{
Shanhui Sun (iD) ${ }^{1,2}$ and Wei $\mathrm{Lu}^{1}$ \\ ${ }^{1}$ College of Mathematics and Statistics, Suzhou University, Suzhou, Anhui, China \\ ${ }^{2}$ School of Economics and Management, China University of Mining and Technology, Xuzhou, Jiangsu, China \\ Correspondence should be addressed to Shanhui Sun; shanhuisun@ahszu.edu.cn
}

Received 15 December 2020; Revised 11 January 2021; Accepted 1 February 2021; Published 15 February 2021

Academic Editor: M. Irfan Uddin

Copyright (c) 2021 Shanhui Sun and Wei Lu. This is an open access article distributed under the Creative Commons Attribution License, which permits unrestricted use, distribution, and reproduction in any medium, provided the original work is properly cited.

\begin{abstract}
To evaluate the performance of rural land circulation mode through the analytic network hierarchy process, based on the results of the performance evaluation with analytic network process, we implemented efficiency analysis on five types of rural land circulation mode by two improved efficiency analytic procedures. Finally, we implemented sensitivity analysis for each criterion layer of the evaluation index system with the performance evaluation data, interpreted five types of rural land circulation mode from three perspectives including benefits, costs, and risks with sensitivity analysis results, and drew related conclusions including higher revenue which will lead to smaller difficulty of the rural land circulation. Cost variables were negative variables of the selected rural land circulation mode, and higher risk would lead to the greater difficulty of rural land circulation and related conclusions.
\end{abstract}

\section{Introduction}

At present, the phenomenon of rural land circulation is very popular. Although the expansion of its scope can make the effective use of existing rural land to a certain degree, there have still been many problems. For example, the traditional concept of farmers restricting the circulation of rural land, imperfection of rural land circulation affecting the rural land circulation, potential risks of the rural land circulation of the village, and difficulties which were encountered in the rural land management lead to many problems including slowing speed of the rural land circulation, circulation size being uneven, and management being lagging. In 2014, "Opinions on Guiding the Orderly Circulation of Rural Land Management Right and Developing Moderate Scale Management of Agriculture" of the CPC Central Committee and State Council pointed out that with industrialization, informatization, urbanization, and agricultural modernization of China, the rural labor force has been transferred a lot, the level of agricultural material technology and equipment has been continuously improved, and the circulation of management rights of farmer contracted land has significantly sped up, so the development of moderate scale operation has become an inevitable trend [1]. Practice has proved that land circulation and moderate scale management are the only way to develop modern agriculture, which is beneficial to optimizing the allocation of land resources, improving labor productivity, ensuring food security and the supply of major agricultural products, promoting the popularization of agricultural technology, and increasing agricultural efficiency and farmers' income, which should be actively and steadily prompted from China's reality where many populations are much more than the land and rural situations are very different. According to the wishes of farmers, where there are moderate conditions, it is possible to unify a piece of farmland, quantify the land with folding stocks, confirm a right of the households, distribute the operating income according to shares, guide farmers to take shares in contracted land and form a land share cooperative organization, to develop agricultural scale management by self-management or commissioned operations, and allow farmers to take stakes in the development of agricultural 
industrialization management with their contractual management rights [2].

Rural land circulation mode refers to different ways used to realize rural land circulation. This paper mainly studies five types of land circulation modes, such as subcontract, lease, contract after rental, share cooperation, and land trust. Subcontract refers to the land contractual management contractors retransferring their lands to a third party and forming a new relationship between these two parties; after subcontracting, the original land contracting relationship remains unchanged [3]. Rental refers to the leasing party collecting certain land income from the behavior of renting or transferring part or all of the land management rights between the contracted farmer and the lessee. Subcontracting and leasing are pretty common ways of land circulation at present. Contract after rental contract refers to the way of land management where the village committee will consolidate the land contracted to the household through the lease form to the collective (which named as a rental), to get unified planning, and then contract the right to use the land to a large agricultural household or an agricultural management company through the market (called contract). Share cooperation refers to farmers contract land management rights as the shares to take part in the jointstock or stock cooperative system management, and get dividend according to the operating efficiency of shares. As enterprises and agricultural cooperatives drive rural land circulation, the development of cooperative shares has become an inevitable trend. Land trust refers to the landowner (client) trusting lands to a trustee, for the effective use of land and improving the development and operational efficiency of the real estate, and the trustees use their professional planning and management to deliver the profit as a trust beneficial distribution to the beneficiary [4]. The trust periods for most of the lands are between 30 and 50 years.

Performance refers to the achievement of accomplishing a certain task or achieving a certain goal, and the result of the organization's expectation refers to the effective output of the organization at different levels to achieve its goals. Therefore, performance can be seen as a process and the result of this process. From the perspective of management, performance is a quantifiable process in the evaluation of managerial performance, which is a measurable outcome variable, that is, the quantification of the related effects of processes and activities. The performance of rural land circulation refers to the influence of rural land circulation behavior on rural economic and social development results, which embodied the income, energy efficiency, and risk performance of rural land circulation, as well as comprehensive performance [5]. Performance evaluation of rural land circulation refers to evaluating income, energy efficiency, and risk performance of rural land circulation rigorously and scientifically, with the use of scientific theories and evaluation methods, to provide a scientific basis for the optimal selection of rural land circulation mode.

According to different rural land transfer modes, the evaluation index system is determined by strict selection principles. Therefore, the performance of rural land transfer can be studied through sensitivity analysis and performance evaluation indicator system of the rural land transfer model. Based on performance analysis of the different modes of rural land circulation, through sensitivity analysis, the article analyzes and sorts the different modes of rural land circulation from three aspects of benefit, cost, and risk. Then, the article does comparative analysis research to achieve the purpose of the performance evaluation of rural land circulation mode. There are two main innovations in this paper. One is to use two improved efficiency analysis methods to study the performance evaluation and efficiency analysis of the rural land transfer model based on the ANP model. Second, the sensitivity analysis is introduced into the performance evaluation of rural land transfer mode, and the rural land transfer mode is studied from three aspects of benefit, cost, and risk.

\section{Performance Evaluation, Sensitivity Analysis, and Analytic Network Hierarchy Process (ANP) of the Land Circulation Mode}

\subsection{Research Status of Performance Evaluation on Land Circulation at Home and Abroad}

2.1.1. Promotion of the Land Circulation Mode to Economy. Research on the economic promotion of land circulation mode is mainly embodied in the aspects of land scale management, financial service system, social security system, and shared development achievements, etc. Teklu and Lemi [6] believed that whether the rural households expand the scale of land management was positively correlated with the quantity of household available labors and live-stocks and negatively related to the quality of land [6]. Bingswanger and Deininger [7] believed that, due to the lack of a sound financial services system and social security system in most developing countries, most countries that have carried out land system reforms have experienced land concentration and polarization under the influence of the market mechanism, resulting in a decline in economic efficiency, even at the expense of certain social stability [7]. Shao and $\mathrm{Hu}$ [8] briefly introduced the main land circulation mode in China in the perspective of safeguarding farmers' rights and interests, constructed the index evaluation system, evaluated its performance, and put forward some optimization suggestions based on the actual research data and quantitative point of views [8]. Yan et al. [9] believed that the performance evaluation of agricultural industrialization was an important basis for the optimal selection of land circulation mode. They thought that, in the process of land circulation, the effect of both the government promoting and market driving evaluation is embodied on whether it can bring the farmers' excess income and stimulate the local modern agricultural to upgrade and get the economic sustainable development at the same time [9].

2.1.2. Comparison of Land Circulation Mode and Performance Evaluation. The comparison of land circulation mode and the research of performance evaluation mainly is comparing the economic benefit, work efficiency, social 
effect, and other efficiencies of different land circulation modes. Dong [10] has compared the conditions of land transactions around the world and pointed out that the former socialist countries of Eastern Europe, which had generally privatized rural land in the early 1990s, imposed strict restrictions on the free trade of the rural land. Compared with rural land ownership transaction, the rural land lease is more effective and widely used. The credit risk caused by rural land leasing is much smaller than that of rural land ownership, whose impact on rural land resource allocation and the whole social stability is much smaller [10]. Dong et al. [11] have summed up three types of land circulation modes including private agent, government agent, and market agent modes and made a comparative analysis on the performance of land agency under various modes according to the present situation of land circulation in our country and based on a large number of field investigations in counties and cities of six provinces [11]. Participating in the land market had a positive role in the transformation of farmland utilization, and the transformation number of farmland utilization was increasing as the land is closer to the county. In terms of the labor transfer, it led to the transfer of employment, which in turn facilitated the possibility of land circulation; on the other hand, the increase of labor income also promoted the circulation of rural land. In addition, the transformation of farmland utilization also showed an obvious regional difference.

2.1.3. Research on the Application Countermeasure of Land Circulation Mode Selection. Foreign research on the application countermeasure of land circulation mode selection mainly focuses on the case analysis, decision analysis, performance evaluation, and so other aspects. Latruffe and Piet [12] surveyed the phenomenon of agricultural land decentralization in western Brittany, France, and studied whether the fragmentation of rural land would affect farmers' decisionmaking and have a negative or positive effect on the farm performance [12]. The paper has used the data from the French agricultural accounting data network (FADN), chose production cost, yield, income, profitability, technology, and scale efficiency as the performance evaluation indicators, and described and regressed the rural land fragmentation, which studied that various dimensions affecting farm performance were related to each other, and the impacts of performance indicators were in line with the expectations. Therefore, policymakers might decide which performance dimension they prefer to choose firstly, in order to choose the most effective way. Wang [13] pointed out that the use of joint ventures in the form of land circulation combines and uses various important factors of production perfectly, to achieve efficient and large-scale operation [13]. He Zhenhua believed that the improvement of land productivity meant that the important factors of production have changed in nature after the land has been circulated, which showed that simple circulation could not change the productive efficiency of the land.

In fact, rural land trade can be realized through a rural land sale or rural land leasing in most of the countries; therefore, the market of rural land exchange is composed of two parts, which are rural land trading market and rural land leasing market. Under the conditions of commodity economy, the transaction of rural land ownership is one of the ways to achieve the optimal allocation of rural land resources and the growth of wealth. Therefore, it is very necessary to evaluate the performance of rural land circulation mode, so as to guide people to make a rational allocation of the resources.

2.2. Sensitivity Analysis and Its Application. Sensitivity analysis refers to the assumption that the model is expressed as $y=f(\mathrm{x} 1, \mathrm{x} 2, \ldots, \mathrm{xn})(\mathrm{xi}$ is the ith value of the mode attribute), so that each attribute changes within the range of possible values and then studies and predicts the influence degree of these attribute changes on the model's output value [14]. The magnitude of the impact is referred to as the sensitivity coefficient of the attribute, and a greater sensitivity coefficient represented a greater impact of the attribute on the model output. The core purpose of sensitivity analysis is to analyze the attribute of the mode, get the sensitivity coefficient of each attribute, remove the attribute with a smaller sensitivity coefficient experientially in practical application, and focus on the attribute with a larger sensitivity coefficient. This can greatly reduce the complexity of the mode, as well as the workload of data analysis and processing, and has greatly improved the accuracy of the mode, while researchers also can use the sort results of sensitivity coefficient of each attribute to resolve the corresponding problem.

The sensitivity analysis is simple and quick in the calculation, so it has high maneuverability, which is used in a lot of practical applications. Since the sensitivity analysis method is operated on the basis of the model, we can also divide it into two types of model and mode-free according to the different modeling methods. As for the data analysis problems which are to be solved, if we know its internal mechanism well, we can accurately get the model representation $y=f(x)$; then, we can analyze the sensitivity directly on this basis, but this is very rare in practical matters. In most cases, it is impossible to understand the internal laws clearly or model the mechanism in face of the huge data. Therefore, people used statistical knowledge to build models in early studies; the most common one is the multivariate linear regression model.

\subsection{Analytic Network Hierarchy Process (ANP), Mathematical Modeling, and Its Software Implementation}

2.3.1. Introduction to Analytic Network Hierarchy Process. Analytic network hierarchy process (ANP) is a more scientific and effective decision method considering the relationship between the elements in each layer of the system and the feedback effect of the lower elements on the upper element and can describe the relationship between the objective things more accurately. The weight of each criterion in the control layer can be obtained by the AHP method [15]. The second part is the network layer; it is a network structure with internal interaction, being composed 
of all the elements of the control layer; the elements are interdependent and mutually dominated; elements and layers are internally independent; each rule of the hierarchical structure of the hierarchy dominates not a simple internal independent element but an interdependent and interacting network structure.

\subsubsection{Mathematical Modeling Process of Analytic Network} Hierarchy Process. In the network analysis method, each element of an element group affecting other elements in the system is also implemented by the decision matrix tool. The pairwise comparison method is used to compare the elements in pairs to obtain the weights indirectly.

2.3.2.1 Construction of Unweighted Super Matrix. Let the control layer of ANP have elements $p_{1}, p_{2}, \ldots, p_{m}$; the network layer under the control layer has element groups $C_{1}, C_{2}, \ldots, C_{N}$, among which, $C_{i}$ contains the element $e_{i 1}$, $e_{i 2}, \ldots, e_{i n_{i}}, i=1,2, \ldots, N$. At first, the criterion $p_{s}(s=$ $1,2, \ldots, m)$ selected in the construction of the network is taken as the main criterion, element $e_{j l}\left(l=1,2, \ldots, n_{j}\right)$ in a certain element group $C_{j}$ of this network is taken as the secondary criterion, and the element $C_{j}$ in the element group is compared according to its influence on $e_{j l}$; that is, the judgment matrix under the main criterion $p_{s}$ is constructed, which gives the sorting vector $\left(w_{i 1}^{(j l)}, w_{i 2}^{(j l)}, \ldots, w_{i n_{i}}^{(j l)}\right)^{T}, l=1,2, \cdots, n$.

Under the $p_{s}$ criterion, if there are $n_{j}$ elements in $C_{j}$, it may need to construct $n_{j}$ judgment matrices to perform operations to form $n_{j}$ sort vectors. It can be seen that these calculations are very huge, and manual calculation is very difficult. The sorting vectors are summarized to obtain a matrix $W_{i j}$ :

$$
W_{i j}=\left(\begin{array}{cccc}
w_{i 1}^{j 1} & w_{i 1}^{j 2} & \ldots & w_{i 1}^{j n_{j}} \\
w_{i 2}^{j 1} & w_{i 2}^{j 2} & \ldots & w_{i 2}^{j n_{j}} \\
\ldots & \ldots & \ldots & \ldots \\
w_{i n_{i}}^{j 1} & w_{i n_{i}}^{j 2} & \ldots & w_{i n_{i}}^{j n_{j}}
\end{array}\right) .
$$

The column vector of $W_{i j}$ here is the sorting vector of the degree of influence of each element in the ith element group on a certain element in the $\mathrm{j}$-th element group. If the element in $C_{j}$ is not affected by the element in $C_{j}$, then $W_{i j}=0$.

There are often multiple element groups in the ANP structure, which needs to repeat these steps to determine the impact relationship between elements in each element group.

In this way, we can finally obtain the unweighted supermatrix $W$ under criterion $p_{s}$.

$$
W=\left(\begin{array}{cccc}
w_{11} & w_{12} & \ldots & w_{1 N} \\
w_{21} & w_{22} & \ldots & w_{2 N} \\
\ldots & \ldots & \ldots & \ldots \\
w_{N 1} & w_{N 2} & \ldots & w_{N N}
\end{array}\right) .
$$

Similarly, other criteria are taken as the main criteria to construct the unweighted hypermatrices, respectively, with a total number of $m$, which are nonnegative matrices, where the subblock $W_{i j}$ of the supermatrix is normalized.

2.3.2.2 Construction of Weighted Supermatrix. $W$ is known as the unweighted supermatrix, which cannot finally show the priority of each element mainly because it is not a normalized matrix; it also needs to compare the pairs of element groups in order to transform the unweighted supermatrix into the weighted supermatrix.

Taking $p_{s}$ as the main criterion and element group $C_{j}$ as the subcriteria, we compare the element groups in pairs, to construct the judgment matrix, and normalize eigenvectors which are obtained to get the normalized eigenvector $\left(a_{1 j}, a_{2 j}, \ldots, a_{N j}\right)^{T}$, which makes it possible to obtain a weight matrix $A$ that reflects the relationship between element groups under a certain criterion.

$$
A=\left(\begin{array}{cccc}
a_{11} & a_{12} & \ldots & a_{1 N} \\
a_{21} & a_{22} & \ldots & a_{2 N} \\
\ldots & \ldots & \ldots & \ldots \\
a_{N 1} & a_{N 2} & \ldots & a_{N N}
\end{array}\right) .
$$

Weight elements of the unweighted supermatrix $W$ are

$$
\bar{W}_{i j}=a_{i j} W_{i j}, \quad i, j=1,2, \ldots, N .
$$

The weighted supermatrix can be obtained, whose sum of each line is 1 , named line random matrix. For simplicity, the following mentioned matrices are weighted supermatrix and are still represented by the symbol.

2.3.2.3 Construction of Extreme Supermatrix. Let the element of the (weighted) supermatrix $W$ be $\omega_{i j}$, let $\omega_{i j}$ be a direct comparison of element $i$ and element $j$, and let $\sum_{k=1}^{N} \omega_{i k} \omega_{k j}$ be the indirect relationship of element $i$ and element $j$; we call it a two-step dominance degree, which is the element of $W^{2}$, and it is normalized. The complex indirect relationship between element $i$ and element $j$ can also be reflected by the iteration of the supermatrix. Thus, $W^{t}$ gives value preference measurements of the indirect influence degree of the decision-makers. When $W^{\infty}=\lim _{t \rightarrow \infty}$ $W^{t}$ exists, the $j$ th column of $W^{\infty}$ is the extreme relative ordering vector of each element in the network layer under $p_{s}$. Therefore, the stable element priority is determined by the method of finding the limit supermatrix in ANP.

In fact, the procedure of finding the limits of ultramatrix is a process of iteration and tends to be stable, which is equivalent to a Markov process. Because of different forms of the elements interacting in the network, the limits of ultramatrix may have two kinds of results: one is that all the column values of the matrix are the same, and then the convergent result is taken as the comprehensive weight; the other is the limit cycle matrix of the block, and then the average value is taken as the comprehensive weight. The calculation of the above analysis is very complex; it is almost impossible to complete the work with manual calculation, which needs to be achieved with the relevant software. 
2.3.3. Software Implementation of Analytic Network Hierarchy Process: Super Decisions. The software Super Decisions has become a major tool for solving ANP problems in engineering practice at the present. Based on the ANP theory, the software programs the calculation of ANP, which lays a foundation for the popularization of the ANP method. The software SD can calculate any ANP model and can fully express the calculation results. Of course, if it does not input correlations between the elements, the software can also be used to calculate the AHP. The basic steps of implementing SD software to make decisions are as follows: build a new model structure, establish the subnet, name the cluster and node, edit set of the elements, link nodes to complete set of the subnet, and input and compare data of the value, to implement a variety of needed calculations.

\section{Mathematical Modeling of Performance Evaluation of Agricultural Land Circulation Mode}

\subsection{Principle of Selecting the Index System}

3.1.1. Principle of Operability. The selection of indexes should not only be scientific, objective, and practical but also should consider the difficulty of selected indicators quantification and the availability of data; each evaluation index should have a clear concept and the data characteristics of facilitating statistics and operability. In the process of selecting evaluation indicators, this paper tries to make the selected indicators easy to quantify, so as to facilitate scientific evaluation successfully.

3.1.2. Scientific and Systematic Principles. Design evaluation should be based on science, each indicator should be clear in connotation, the calculation method should be concise, and indicators at the same level should be relevant and independent. Evaluation of the system design should comprehensively consider all aspects of the rural social-economic development; selected indicators should be as overall and comprehensive as possible and can reflect the economic performance, social performance, ecological performance, and other performances brought by the rural land circulation objectively and truly, in order to achieve the scientific integrity of the evaluation objectives.

3.1.3. Principle of Representativeness. Because rural socialeconomic development is affected by many aspects, rural land circulation is only one of them. Consequently, indicator selection of the performance evaluation of rural land circulation should be typical and representative; the chosen indicator should be related to the factor "rural land circulation" and should be able to accurately reflect the rural economic, social, and ecological effects brought by the rural land circulation factor, as well as objectively and reasonably reflect the performance of rural land circulation.
3.1.4. Principle of Comparability. For the comparative analysis of the rural land circulation performance with different modes, the selected indicators should be comparable, so as to facilitate comparisons between different modes and regions, to provide a scientific basis for circulation performance improvement of the rural land circulation mode selection.

3.2. Determination and Interpretation of the Indicator System. The principle of evaluation index system mainly includes operable principle, scientific and systematic principle, representativeness principle, and comparability principle. The ANP model requires that each index should not only represent the main aspects of the research target but also take into account the relationship between the indicators. Combining the above two aspects, based on the main evaluation problems of rural land transfer mode, this paper scientifically and comprehensively considers the performance evaluation index system of rural land transfer mode. According to the performance evaluation target of rural land circulation mode, the evaluation system consists of three layers including the target layer, the criterion layer, and the indicator layer. There is only one target layer, which is the result of the performance evaluation of rural land circulation. The criterion layer is divided into three parts, named benefit, energy efficiency, and risk separately, and the indicator layer of each criterion layer is divided into a number of indicators. The construction and meaning of the specific indicator system are shown in Table 1 .

\subsection{The Whole Modeling Idea Determination of Comparison Values among the Indicators of Land Transfer Mode Performance Evaluation}

3.3.1. The Whole Modeling Idea of Analytic Network Process (ANP). Benefits, opportunities, costs, and risks of the decision often will be taken into account in the ANP decision analysis, and the model formed by the comprehensive effects of the above four aspects is called the BOCR model. This study mainly analyzed performance evaluation problems of the land circulation mode, it is difficult to define and quantify the land circulation expression in terms of the opportunity, but it will highlight the lack of attention to this part if the indicators of opportunity are not expressed. In order to solve this problem better, considering that opportunity represents the potential benefits of the land circulation, this paper incorporated opportunities into the indicator system of benefits. Considering the decisionmaking problems from the perspective of the evaluator, where if it chooses a particular mode of cooperation, the demand side of the service will gain a variety of direct and potential benefits, there are various uncertain risk factors associated with service providers in relation to the costs associated with gaining revenue and development opportunities. 
TABLE 1: Index system and its explanation of performance evaluation of the rural land circulation mode.

\begin{tabular}{l}
$\begin{array}{l}\text { Criterion } \\
\text { layer }\end{array}$ \\
\hline $\begin{array}{c}\text { Indicator layer } \\
\text { B1 change rate of farmers' per capita net } \\
\text { income }\end{array}$ \\
B3 the realization index of rural land scale \\
management \\
Bevel change rate of the number of agricultural \\
practical talents number
\end{tabular}

Benefit B5 income change rate of the receiving unit (personal)

B6 income change rate of the government tax revenue

B7 change rate of rural unit land use

B8 change rate of farmers' pension and medical improvement

B9 change rate of rural children's schooling education

(Farmers' per capita net income after the circulation - farmers' per capita net income before the circulation)/Farmers' per capita net income before the circulation

(Agricultural industrialization level after the circulation - agricultural industrialization level before the circulation)/Agricultural industrialization level before the circulation

(Rural land scale management after the circulation - rural land scale management before the circulation)/Rural land scale management before the circulation

(Number of agricultural practical talents after the circulation - number of agricultural practical talents before the circulation)/Number of agricultural practical talents before the circulation

(Income of the receiving unit (personal) after the circulation income of the receiving unit (personal) before the circulation)/Income of the receiving unit (personal) before the circulation

(Income of the government tax revenue after the circulation income of the government tax revenue before the circulation)/Income of the government tax revenue before the circulation

(Size of rural unit land use after the circulation size of rural unit land use before the circulation)/Size of rural unit land use before the circulation

(Farmers' pension and medical level after the circulation - farmers'

pension and medical level before the circulation)/Farmers' pension and medical level before the circulation

(Schooling education level of rural children after the circulation schooling education level of rural children before the circulation)/

Schooling education level of rural children before the circulation

(Agricultural science and technology investment after the circulation agricultural science and technology investment before the circulation)/ Agricultural science and technology investment before the circulation

(Mechanical use number of unit rural land after the circulation -

mechanical use number of unit rural land before the circulation)/

mechanical use number of unit rural land before the circulation

(Use number of seed, fertilizer, and pesticide used in unit rural land after the circulation - use number of seed, fertilizer, and pesticide used in unit rural land before the circulation)/Use number of seed, fertilizer, and pesticide used in unit rural land before the circulation

Energy C3 cost change rate of seed, fertilizer, and pesticide use in rural lands

C4 investment change rate in environmental protection of the rural land

(Environmental protection investment of rural lands after the circulation environmental protection investment of rural lands before the

circulation)/Environmental protection investment of rural lands before the circulation

C5 costs of the land ownership and circulation Sum of all kinds of cost generated in processes of the land ownership and circulation

R1 change rate of rural Gini coefficient

(Rural Gini coefficient after the circulation - rural Gini coefficient before the circulation)/Rural Gini coefficient before the circulation

R2 change rate of rural Engel coefficient

R3 change rate of farmers' effective

Risk employment time

(Rural Engel coefficient after the circulation - rural Engel coefficient before the circulation)/Rural Engel coefficient before the circulation

(Effective employment time of farmers after the circulation - effective employment time of farmers before the circulation)/Effective employment time of farmers before the circulation

(Food production after the circulation - food production before the circulation)/Food production before the circulation

R4 food security index

R5 risks of land circulation operating losses and The total enterprises' number of losses and the breach of contract midway/

$\mathrm{R} 5$ risks of land circulation operating losses and The total enterprises' number of losses and the breach of contract midway/
the breach of contract midway
Total number of the transferred enterprises the breach of contract midway

R6 land circulation procedure and contract management risk

Nonstandard land circulation procedures and nonstandard contract number/Total number of the transferred contract

3.3.2. Model Construction and Analysis between the Clusters. Based on consideration of rural land circulation mode performance evaluation, the paper established a model for the performance evaluation of rural land circulation mode, and the target layer only had one goal, that is, the performance evaluation of rural land circulation mode. There were 
three criteria layers in the model module, which were the benefit, energy efficiency, and risk, respectively. Each criterion layer had the respective indicator layers under them; furthermore, five categories of an embodiment comprise rural land circulation mode. The association of each element in the criteria layer with the elements of each project reflects the impact of each criterion on the alternative. Since each element in each project is associated with an element in the criteria group, which reflected the internal dependence of the elements in the alternative indirectly by feedback, therefore, there is no need for internal pairwise comparison.

\subsection{Determination of the Comparison Value of Criteria Layer in the Model}

3.4.1. Determination of the Comparison Value of the Criterion Layer under the Indicator Layer. Based on the perspective of the performance evaluation of the land circulation mode, by analyzing the role of benefit, energy efficiency, and risk in the process of rural land circulation, seeking experts' opinion and repeated argumentation, the comparison value of the criterion layer under the indicator layer was finally determined; the details are shown in Table 2 .

3.4.2. Determination of the Comparison Value between the Criteria Layer and the Alternative. We compared the alternative group with benefit, energy efficiency, and risk, etc. of the criteria layer three times. Based on analysis of the relationship between the benefit and the alternative, by consulting the experts and repeated demonstration, the comparison value was finally determined between the criteria layer and the alternative selection, and the details are shown in Table 3.

\subsubsection{Determination of the Comparison Value between the} Indicator Layer and the Alternative. There was a direct relationship between the indicator later under the criteria layer and the alternative, which was implemented by the expert scoring method. But the indicator layer had plenty of elements; it is impossible to enumerate the comparison of various rural land circulation modes from the perspective of all indicators here. As in the following, comparison scores of the five categories of rural land circulation mode are given, from the perspective of farmers' per capita net income benefit (Table 4).

\section{Efficiency Analysis of Rural Land Circulation Mode}

4.1. The Concept and Function of Efficiency Analysis. Performance analysis refers to an ability measurement algorithm that determines and analyzes the objectives according to the main factors that influence the performance, using general system analysis method, based on the collection of information, and establish a comprehensive reflection of something to reach a predetermined target, which can finally give the measured effectiveness result of a certain thing.
4.2. Two Types of Improved Performance Analysis. Traditional performance analysis is using the simple quotient ratio formula; the specific formula is

$$
P_{0}=\frac{B}{\mathrm{CR}} \text {. }
$$

After the introduction of performance analysis, the analysis of the problem is not just a weighted sorting process but also a process of trade-offs. Thus, the paper proposed two improved effectiveness analysis methods, where the basic idea was combining the weights of these three clusters in the criteria layer with traditional performance analysis formulas; there are two improvement directions in the specific expression process [16].

The first improved efficacy analysis is the weighted quotient ratio formula, i.e.,

$$
P_{1}=\frac{a_{1} \times B}{a_{2} \times C+a_{3} \times R} .
$$

The second improved efficacy analysis is the weighted difference ratio formula, i.e.,

$$
P_{2}=a_{1} \times B-a_{2} \times C-a_{3} \times R .
$$

The results of the efficacy analysis and ranking of rural land circulation performance were studied later using traditional performance analysis formulas and these two improved performance analysis formulas.

\subsection{Efficacy Analysis of Rural Land Circulation Mode Performance Evaluation}

4.3.1. Weight and Result Analysis of the Cluster. The final weight redistribution result of the three clusters in the criterion layer was obtained based on the analytic network process; the details are shown in Table 5.

4.3.2. Weighted and Result Analysis in Criteria Layer of the Rural Land Circulation Mode. With the software Super Decisions, weight results of the cluster in three criteria layers to the five types of criteria layer of the rural land circulation mode are shown in Table 6.

4.4. Efficiency Analysis of the Rural Land Circulation Mode. The weight analysis results of the cluster and the weight results of the rural land circulation mode under the criteria layer were adopted to represent the results of rural land circulation mode efficiency evaluation, based on traditional efficiency evaluation formula and improved efficiency evaluation formulas; the details are shown in Table 7.

Circulation results of three efficiency analyses were obtained based on five types of rural land circulation modes including subcontract, lease, contract after rental, share cooperation, and lands trust, whose results were ranked. Results of the ranking are shown in Table 8.

It can be seen that the subcontracting income was higher, with comparison analysis, whose ranking was systematically defaulted better than the lease; however, both the energy 
TABLE 2: Criteria layer comparison value list of the rural land circulation mode performance evaluation.

\begin{tabular}{lccc}
\hline Goal & Benefit & Energy efficiency & \\
\hline Benefit & 1.00 & 7.12 & Risk \\
Energy efficiency & 0.14 & 1.00 & 4.95 \\
Risk & 0.20 & 0.91 & 1.10 \\
\hline
\end{tabular}

TABLE 3: Criteria layer and the alternative selection comparison value list of the rural land circulation mode performance evaluation.

\begin{tabular}{lcc}
\hline Inconsistency & Alternatives & Benefit \\
\hline Alternatives & 1 & 0.4 \\
Benefit & 2.5 & 1 \\
Inconsistency & Alternatives & Energy efficiency \\
Alternatives & 1 & 0.3333 \\
Energy efficiency & 3 & 1 \\
Inconsistency & Alternatives & Risk \\
Alternatives & 1 & 0.6667 \\
Risk & 1.5 & 1 \\
\hline
\end{tabular}

TABLE 4: Indicator layer and the alternative selection comparison value list of the rural land circulation mode performance evaluation.

\begin{tabular}{|c|c|c|c|c|c|}
\hline Change rate of farmers' per capita net income & Subcontract & Lease & Contract after rental & Share cooperation & Land trust \\
\hline Subcontract & 1.0000 & 1.4600 & 0.4292 & 0.2315 & 0.2667 \\
\hline Lease & 0.6849 & 1.0000 & 0.3623 & 0.2070 & 0.2427 \\
\hline Contract after rental & 2.3300 & 2.7600 & 1.0000 & 0.4237 & 0.5348 \\
\hline Share cooperation & 4.3200 & 4.8300 & 2.3600 & 1.0000 & 1.3500 \\
\hline Land trust & 3.7500 & 4.1200 & 1.8700 & 0.7407 & 1.0000 \\
\hline
\end{tabular}

TABLE 5: Cluster weight results of the rural land circulation mode performance evaluation.

\begin{tabular}{lcr}
\hline No. & Cluster group & Weight \\
\hline 1 & Benefit & No. $1=0.7479$ \\
2 & Energy efficiency & No. 2=0.1224 \\
3 & Risk & No. 3=0.1297 \\
\hline
\end{tabular}

TABLe 6: Scores' list in each model criteria layer of the rural land circulation mode performance evaluation.

\begin{tabular}{lcccc}
\hline No. & Alternatives & Benefit & Energy efficiency & Risk \\
\hline 1 & Subcontract & 0.0897 & 0.1610 & 0.1498 \\
2 & Lease & 0.0880 & 0.1576 & 0.1479 \\
3 & Contract after rental & 0.1501 & 0.1796 & 0.1778 \\
4 & Share cooperation & 0.3602 & 0.2591 & 0.2776 \\
5 & Land trust & 0.3120 & 0.2427 & 0.2469 \\
\hline
\end{tabular}

TABLe 7: The efficiency analysis list of the rural land circulation mode.

\begin{tabular}{lccccccc}
\hline No. & $\begin{array}{c}\text { Circulation } \\
\text { methods }\end{array}$ & Benefit & $\begin{array}{c}\text { Energy } \\
\text { efficiency }\end{array}$ & Risk & $\begin{array}{c}\text { Traditional performance } \\
\text { evaluation }\end{array}$ & $\begin{array}{c}\text { Improved efficiency } \\
\text { evaluation 1 }\end{array}$ & Improved efficiency evaluation 2 \\
\hline 1 & Subcontract & 0.0897 & 0.1610 & 0.1498 & 3.7192 & 1.7144 & 0.0280 \\
2 & Lease & 0.0880 & 0.1576 & 0.1479 & 3.7754 & 1.7109 & 0.0273 \\
3 & Contract after rental & 0.1501 & 0.1796 & 0.1778 & 4.7005 & 2.4925 & 0.0672 \\
4 & Share cooperation & 0.3602 & 0.2591 & 0.2776 & 5.0079 & 3.9786 & 0.2017 \\
5 & Land trust & 0.3120 & 0.2427 & 0.2469 & 5.2067 & 3.7806 & 0.1716 \\
\hline
\end{tabular}

efficiency and risk were lower than lease, whose rankings were superior to the subcontract.

Share cooperation had the largest benefits, but its energy efficiency and risk were also the highest, and land trust was ranked second in terms of the benefit, energy efficiency, and risk, which showed that the land trust was more effective through the traditional performance evaluation and improved efficiency evaluations [17].

The reason might be the energy efficiency and risk restricted scores of the share cooperation. In the actual 
TABLE 8: Efficiency analysis ranking list of the rural land circulation mode performance evaluation.

\begin{tabular}{lcccccc}
\hline No. & Ranking method & Subcontract & Lease & Contract after rental & Share cooperation & Land trust \\
\hline 1 & Traditional performance evaluation & 5 & 4 & 3 & 2 & 1 \\
2 & Improved efficiency evaluation 1 & 4 & 5 & 3 & 1 & 2 \\
3 & Improved efficiency evaluation 2 & 4 & 5 & 3 & 1 & 2 \\
\hline
\end{tabular}

situation, the rural land circulation parties having limited knowledge of share cooperation and land trust policy, coupled with the relatively fussy circulation procedure, affect the choice of rural land circulation mode in various parties.

\section{Sensitivity Analysis of Rural Land Circulation Mode Performance Evaluation}

The main task of sensitivity analysis is to determine whether the change of a parameter has an impact on the decision result; that is, within what range, the change of this parameter will (or will not) affect the ranking result of the decision, or whether some parameters in the original decision problem are sensitive; that is, if these parameters change slightly, the decision result will be affected. Therefore, when the weight of one target changes, it will inevitably lead to the change of other weights. In order to make the analysis simple, it is assumed that when the weight of one goal changes, only one of the other goal weights will change accordingly, and the other goal weights except these two will remain unchanged in the original decision problem. This paper analyzes the sensitivity of benefit, cost, and risk based on the index system of the land transfer model.

5.1. Benefit. In the ANP model, the longer the step is calculated, the larger the corresponding calculation is; then the calculation accuracy will be higher, and the required time will be longer; this paper selected 7 systematically defaulted steps for calculation. Taking benefit as the independent variable for sensitivity analysis, the sensitivity analysis curve of risk is obtained, with two inflection points of 0.3424 and 0.6973 .

5.1.1. When It Was Less than 0.3421, the Decision Sort Was No. $2>$ No. $1>$ No. $3>$ No. $5>$ No. 4 . This means that for the decision-makers, in the case of not paying too much attention to the benefits, that is, when requirements for the benefits were not high in the rural land circulation process, the decision order would be No. $2>$ No. $1>$ No. $3>$ No. $5>\mathrm{No}$. 4. In the case of not paying attention to the income of land transfer, the main consideration would be two aspects including the energy efficiency and risk of land circulation. Among these five types of the rural land circulation mode, No. 4 stock cooperation and No. 5 land trust had higher energy efficiency and risk, both of the energy efficiency and risk of No. 3 contract after rental were moderate, while those of No. 1 subcontract and No. 2 lease were lower.

Therefore, the above rank reflects the reality of rural land circulation, which is also reasonable.
5.1.2. When It Was Greater than 0.3421 and Less than 0.6973, the Decision Order Would Be No. 4>No. $5>$ No. $3>$ No. $2>$ No. 1. This means that for decision-makers, in the case of paying more attention to the benefits, that is, when requirements for the benefits were high in the rural land circulation process, the decision order would be No. $4>$ No. $5>$ No. $3>$ No. $2>$ No. 1 . No. 4 is the stock cooperation circulation mode, whose risk is relatively higher, but the benefit is the highest, and the stock cooperation circulation mode is called the best choice in the decision-making process here.

\subsubsection{When It Was Greater than 0.6973, the Decision Order} Would Be No. $4>$ No. $5>$ No. $3>$ No. $2>$ No. 1. This means that for the decision-makers, in the case of paying pretty much attention to the benefits, that is, in the case of unwilling to bear more energy efficiency in the process of rural land circulation, the decision order would be No. $4>$ No. $5>$ No. $3>$ No. $1>$ No. 2 .

Compared with the second case, the second case only has the order of No. 1 and No. 2 changed. For a detailed analysis, in the case of very great importance to earnings, compared to higher rental income No. 2 in terms of the subcontract No. 1, No. 2, No. 1, and therefore the order with respect to the second case were changed.

Because the higher income can reduce the rural land circulation difficulty, which means that the income variable is the positive variable of the rural land circulation model choice. Income is the main impetus to promote rural land circulation, which makes income the most important factor compared with the energy efficiency and risk in the choice of rural land circulation model. Therefore, from the sensitivity analysis of income, it can be seen that when the rural land circulation income is not paying too much attention, it is still better to choose the share cooperation and land trust modes with the relatively higher energy efficiency and risk for rural land circulation [18].

5.2. Energy Efficiency. Using energy efficiency as the independent variable for sensitivity analysis, it is concluded that there are two inflection points of 0.1737 and 0.6131 in the sensitivity analysis of energy efficiency.

5.2.1. When It Was Less than 0.1737, the Decision Order Would Be No. $4>$ No. $5>$ No. $3>$ No. $1>$ No. 2. This means that for the decision-makers, without considering the energy efficiency, that is, if they were willing to pay a high energy efficiency during the process of rural land circulation, the decision order would be No. $4>$ No. $5>$ No. $3>$ No. $1>$ No. 2. Without considering the energy efficiency of land 
circulation, the most important aspects for consideration will be the income and risk of the rural land circulation. Risk difference among these five types of rural land circulation modes was not particularly large, so the most important consideration at this moment will be the aspect of income factor. Specifically analyzed, on this condition, No. 4 share cooperation model had the highest income, while No. 2 lease had the lowest one, and the decision order also reflected the above analysis truly.

5.2.2. When It Was Greater than 0.1737 and Less than 0.6131, the Decision Order Would Be No. 4>No. $5>$ No. $3>$ No. $2>$ No. 1. For decision-makers, in the case of not paying much attention to energy efficiency, that is, if they were willing to bear a higher energy efficiency during the process of rural land circulation, the decision order would be No. $4>$ No. $5>$ No. $3>$ No. $2>$ No. 1 . Compared with the second case, the first case only has the order of No. 1 and No. 2 changed. For the specific analysis, considering the energy efficiency, No. 2 lease had higher energy efficiency than that of No. 1 subcontract; therefore, the order of No. 1 and No. 2 has been changed with respect to the first case.

5.2.3. When It Was Greater than 0.6131, the Decision Order Would Be No. $2>$ No. $1>$ No. $3>$ No. $5>$ No. 4 . For decisionmakers, in the case of paying much attention to energy efficiency, that is, if they were not willing to bear a higher energy efficiency during the process of rural land circulation, the decision order would be No. $2>$ No. $1>$ No. $3>$ No. $5>$ No. 4.

Because the higher energy efficiency will increase the rural land circulation difficulty, this means that the energy efficiency variable is the negative variable of the rural land circulation model choice.

The energy efficiency of the rural land circulation is oneoff, while the benefit is for one year or several years. Therefore, with respect to the income of the farmers and the development of the enterprises, local governments are generally willing to pay for the circulation of rural land for guiding and supporting. From the actual sensitivity analysis, it can also be seen that in the case of not paying much attention to the energy efficiency of rural land circulation, share cooperation and land trust modes with higher benefits still tend to be chosen for the rural land circulation.

5.3. Risk. Taking risk as the independent variable for sensitivity analysis, it is concluded that there are three inflection points in the sensitivity analysis of risk: $0.2132,0.4868$, and 0.5868 .

5.3.1. When It Was Less than 0.2132, the Decision Order Would Be No. $4>$ No. $5>$ No. $3>$ No. $1>$ No. 2. This means that for the decision-makers, without considering the risk, that is, if they were willing to pay a high risk during the process of rural land circulation, the decision order would be No. $4>$ No. $5>$ No. $3>$ No. $1>$ No. 2. Without considering the risk of land circulation, the most important aspects for consideration will be the income and energy efficiency of the rural land circulation. Energy efficiency difference among these five types of rural land circulation modes was not particularly large, so the most important consideration at this moment will be the aspect of income factor. Specifically analyzed, on this condition, No. 4 share cooperation model had the highest income, while No. 2 lease had the lowest one, and the decision order also reflected the above analysis truly.

5.3.2. When It Was Greater than 0.2132 and Less than 0.4868, the Decision Order Would Be No. 4>No. $5>$ No. $3>$ No. $2>$ No. 1. For decision-makers, in the case of not paying much attention to risk, that is, if they were willing to bear a higher risk during the process of rural land circulation, the decision order would be No. $4>$ No. $5>$ No. $3>$ No. $2>$ No. 1. Compared with the second case, the first case only has the order of No. 1 and No. 2 changed. For the specific analysis, No. 2 lease had the lowest income, yet No. 1 had the lowest risk in this situation; therefore, the order of No. 1 and No. 2 changed compared with the first case.

5.3.3. When It Was Greater than 0.4868 and Less than 0.5868 , the Decision Order Would Be No. $5>$ No. $4>$ No. $3>$ No. $2>$ No. 1. For decision-makers, in the case of paying some attention to risk, that is, if they were willing to bear a certain risk during the process of rural land circulation, the decision order would be No. $5>$ No. $4>$ No. $3>$ No. $2>$ No. 1 . No. 5 is the land trust circulation mode, whose risk is relatively higher, but the income also is correspondingly higher than the others. The land trust circulation mode is called the best choice during the decision-making process here.

5.3.4. When It Was Greater than 0.5868, the Decision Order Would Be No. $2>$ No. $1>$ No. $3>$ No. $5>$ No. 4 . For decisionmakers, in the case of paying much attention to risk, that is, if they were not willing to bear a higher risk during the process of rural land circulation, the decision order would be No. $2>$ No. $1>$ No. $3>$ No. $5>$ No. 4 .

Because the higher risk will increase the rural land circulation difficulty, this means that the risk variable is the negative variable of the rural land circulation model choice. The above analysis can also be explained by economic theory. When the decision-maker does not want the risk to exist in the process of rural land circulation, the decisionmaker will be the risk aversion; in this case, rural land circulation mode with less risk is usually chosen for the circulation. Accordingly, land circulation mode with lower risk only can bring the smaller income; the corresponding chooses are No. 1 and No. 2 circulation modes.

When the decision-maker is willing to undertake the corresponding circulation risk in the process of rural land circulation, it shows that the decision-maker is a risk enthusiast, in which case, the land circulation mode with greater risk is usually chosen. Accordingly, land circulation mode with higher risk can bring a greater income, and the corresponding choices are No. 4 and No. 5 circulation 
modes. For the moderate risk, No. 3 circulation mode is the corresponding choice.

\section{Conclusion}

The rural land circulation is the product of our country's agriculture and rural development to a certain stage, which is an effective rural land system improvement on the basis of the current household contract responsibility system, and is the breakthrough and key to the new round of rural reform. To sum up, a mode of circulation may be applicable to different regions, or the same region may have a variety of applicable modes; then, the circulation performance of the same type of circulation mode in different regions must be different. For example, the application of land circulation is very wide, which is applicable not only to the economically backward areas but also to the economically developed regions; however, it will bring completely different performance in the two regions of different economic development levels. Therefore, in the process of optimizing the choice of rural land circulation mode, a region must fully integrate its own conditions and adapt to local conditions and the circumstances, so as to give full play to the performance of rural land circulation.

\section{Data Availability}

The data used to support the findings of this study are included within the article.

\section{Conflicts of Interest}

The authors declare they have no conflicts of interest.

\section{Authors' Contributions}

All authors contributed to this paper equally.

\section{Acknowledgments}

This work was supported by the Anhui University $\mathrm{Hu}$ manities and Social Science Research Key Project (SK2019A0526), the Social Science Innovation and Development Research Project of Anhui Province in 2020 (2020CX104), the Key Teaching and Research Project of Provincial Quality Engineering Project of Anhui Universities (2020jyxm2213), Start Project of Scientific Research by Professor and Doctor of Suzhou University (2015JB11), and the massive open online courses (MOOC) of the provincial quality project of Anhui Provincial Higher Education Institutions (2016mooc301).

\section{References}

[1] Y. Ray and R. Forrest, "Elevating the peasants into high-rise apartments: the land bill system in Chongqing as a solution for land conflicts in China?" Journal of Rural Studies, vol. 47, no. 10, pp. 474-484, 2016.

[2] M. S. Allahyari, C. A. Damalas, Z. D. Masouleh, and M. Ghorbani, "Retracted: land consolidation success in paddy fields of northern Iran: an assessment based on farmers' satisfaction," Land Use Policy, vol. 73, no. 4, pp. 95-101, 2018.

[3] J.-D. Gerber, "The difficulty of integrating land trusts in land use planning," Landscape and Urban Planning, vol. 104, no. 2, pp. 289-298, 2012.

[4] M. Uyan, T. Cay, Y. Inceyol, and H. Hakli, "Comparison of designed different land reallocation models in land consolidation: a case study in Konya/Turkey," Computers and Electronics in Agriculture, vol. 110, no. 1, pp. 249-258, 2015.

[5] Z. Jana and S. Rogga, "Transdisciplinarity in land use science-a review of concepts, empirical findings and current practices," Futures, vol. 65, no. 1, pp. 28-44, 2015.

[6] T. Teklu and A. Lemi, "Factors affecting entry and intensity in informal rental land markets in Southern Ethiopian highlands," Agricultural Economics, vol. 30, no. 2, pp. 117-128, 2004.

[7] H. P. Binswanger and G. E. P. Deininger, "Distortions revoltand reforming agrieultural land relations," Handbook of Development Eeonomics, vol. 3, no. 2, pp. 2661-2772, 1993.

[8] F. Shao and X. Hu, "Rural land circulation mode and performance evaluation from the perspective of safeguarding farmers' rights and interests," Economic Research Guide, vol. 12, no. 9, pp. 10-13, 2016.

[9] H. Yan, Z. Wang, T. Zhang, and L. Hong, "Optimization analysis of land circulation based on industrial performance evaluation--a case study of Kedong county, Qiqihar," Private Science and Technology, vol. 22, no. 9, p. 186, 2012.

[10] X.-Y. Dong, "Two-tier land tenure system and sustained economic growth in post-1978 rural China," World Development, vol. 24, no. 5, pp. 915-928, 1996.

[11] G. Dong, L. Li, and J. Ren, "Land circulation model and economic growth performance under property rights agency analysis," Sociological Research, vol. 24, no. 1, pp. 25-63+243, 2009.

[12] L. Latruffe and L. Piet, "Does land fragmentation affect farm performance? A case study from Brittany, France," Agricultural Systems, vol. 129, no. 7, pp. 68-80, 2014.

[13] X. Wang, "Reflections on improving rural land registration system," Rural Management, vol. 22, no. 7, pp. 19-20, 2012.

[14] J.-B. Liu, S. Wang, C. Wang, and S. Hayat, "Further results on computation of topological indices of certain networks," IET Control Theory \& Applications, vol. 13, no. 11, pp. 2065-2071, 2017.

[15] B. C. Ervural, S. Zaim, O. F. Demirel, A. Zeynep, and D. Dursun, "A ANP and fuzzy TOPSIS-based SWOT analysis for Turkey's energy planning," Renewable \& Sustainable Energy Reviews, vol. 82, no. 2, pp. 1538-1550, 2018.

[16] J. B. Liu and S. N. Daoud, "Number of spanning trees in the sequence of some graphs," Complexity, vol. 2019, 2019.

[17] K. H. Koirala, A. Mishra, and S. Mohanty, "Impact of land ownership on productivity and efficiency of rice farmers: the case of the Philippines," Land Use Policy, vol. 50, no. 1, pp. 371-378, 2016.

[18] B. D. Jonida, V. K. Vijesh, A. Zulkifli, and Q. Matin, "Land-use change and livelihoods of non-farm households: the role of income from employment in oil palm and rubber in rural Indonesia," Land Use Policy, vol. 76, no. 7, pp. 828-838, 2018. 